\title{
ПЕДАГОГИКА
}

DOI: $10.17805 /$ trudy.2017.4.1

\section{СИСТЕМНОСТЬ В ЛОГИКЕ РАЗВИТИЯ ПОЗНАВАТЕЛЬНОЙ АКТИВНОСТИ}

\author{
B. А. Ситаров, М. Ю. Шонин \\ Московский гуманитарный университет
}

\begin{abstract}
Аннотация: В статье рассматривается понятие "системность», которое способствует целостности в определении объектов исследования в педагогической науке. Приводятся определение «системы», ее принципы. Рассматриваются элементы теории системного анализа в логике развития познавательной активности.
\end{abstract}

Ключевые слова: система; системность; принципы системы; познавательная активность

\section{SYSTEMATICITY IN THE LOGIC OF DEVELOPMENT OF COGNITIVE ACTIVITY}

\author{
V. A. Sitarov, M. Yu. Shonin \\ Moscow University for the Humanities
}

\begin{abstract}
The article examines the concept "systematicity" that promotes integrity in the definition of objects of research in the pedagogical science. It gives the definition of a "system" and its principles. Elements of the system analysis theory in the logic of development of cognitive activity are considered.
\end{abstract}

Keywords: system; systematicity; principles of a system; cognitive activity

В середине XX века мировая наука претерпела глубокие качественные изменения. Развитие интеграционных процессов как альтернатива тенденции к изучению отдельных явлений привело к появлению ряда особых направлений методологии научного познания и социальной практики. Одним из них является системный подход.

Данное направление методологии к первому десятилетию XXI века завоевало прочные позиции во многих естественных и гуманитарных науках, к числу которых принадлежит педагогика. Как известно, системный поход в педагогике предполагает отношение к ней как к системе 
- совокупности хорошо структурированных и тесно взаимосвязанных между собой элементов (системность элементов).

Известные философы и методологи И. В. Блауберг, Э. Г. Юдин сформулировали системный подход как направление методологии научного познания, в основе которого лежит рассмотрение объекта как системы - целостного комплекса взаимосвязанных элементов (Блауберг, Юдин, 1973).

Такой подход, в отличие от традиционного предметного подхода, является более качественным и современным. Основными приемами исследования при данном подходе являются моделирование, системноструктурный анализ, функциональный, прием анализа и синтеза. В нашем исследовании, посвященное развитию познавательной активности, особый интерес занимает системно-структурный анализ, а также понятие «системность» в логике ее развития. С данной целью рассмотрим категорию «система», ее особенности.

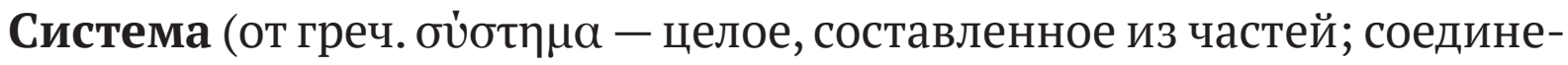
ние), совокупность элементов, находящихся в отношениях и связях друг с другом, которая образует определенную целостность, единство (Философский энциклопедический словарь, 1983: 610). Целостность принято рассматривать как состоящую из частей, называемых элементами данной системы. Важно уточнить, что элементами системы является не только абстрагированные понятия, но и отношения между ними.

Изучить систему - значит определить элементы системы. Элементы, которые полностью не удается идентифицировать, т. е. не удается установить отношения с другими элементами системы, имеют эти отношения с окружением этой системы, с наблюдателем или со средой и называются входами (выходами) системы. При выходе из одной системы неизбежен вход в иную систему - в этом отражается всеобщая взаимосвязь событий и явлений в мире. Объектами системы называются компонентами системы, формулирующиеся на основе заданных критериев.

Общие свойства систем произвольной природы - выделение в них некоторых стандартных компонентов и типов взаимодействия между ними. Эти компоненты поддаются формализации в различных языках и доступны различным способам логической обработки.

Академик П. К. Анохин определил систему как «образование, состоящее не из любых, а из избирательно вовлеченных компонентов, в некую целостность, взаимосвязанных и взаимодействующих между собой» (Анохин, 1978: 15).

Данным понятием пользуются в различных областях познания, так как каждая наука имеет дело с изучением и применением на практике сложных системных объектов и должна находить способы их точного описания, исследования и построения. 
Методолог Ю. И. Черняк выделил следующие принципы системы:

- целостность, отражающаяся в том, что совокупность объектов, рассматриваемых в качестве системы, представляет собой некое единство, обладающие общей целью и свойствами;

-делимость, заключающаяся в том, что объект совокупности рассматриваются в качестве состоящий из элементов;

- изолированность, отождествляющаяся с возможностью выделить комплекс объектов из системы и рассматривать изолированно;

- идентифицируемость: каждая составляющая часть системы (элемент) может быть отделена от других;

- разнообразие (множественность): каждый элемент системы обладает собственным поведением и состоянием, отличным от поведения и состояния, входящих в систему элементов, и системы в целом;

- наблюдаемость: все входы и выходы системы контролируемы наблюдателем, либо, по крайней мере, наблюдаемы;

- неопределенность: наблюдатель не может одновременно фиксировать все свойства и отношения объектов системы и именно с целью их выявления осуществляет исследование (Черняк, 1975: 193).

Познавательная активность, как один из важнейших факторов успешной реализации учебного процесса, является предметом множества научных изысканий. Мы полагаем, что ее рассматривать следует как сложную, динамически развивающуюся систему, структура которой усложняется по мере перехода на более высокую ступень развития. Ее примером может послужить система, представленная на рисунке 1. Убедимся, что она удовлетворяет принципам системности Ю. И. Черняка.

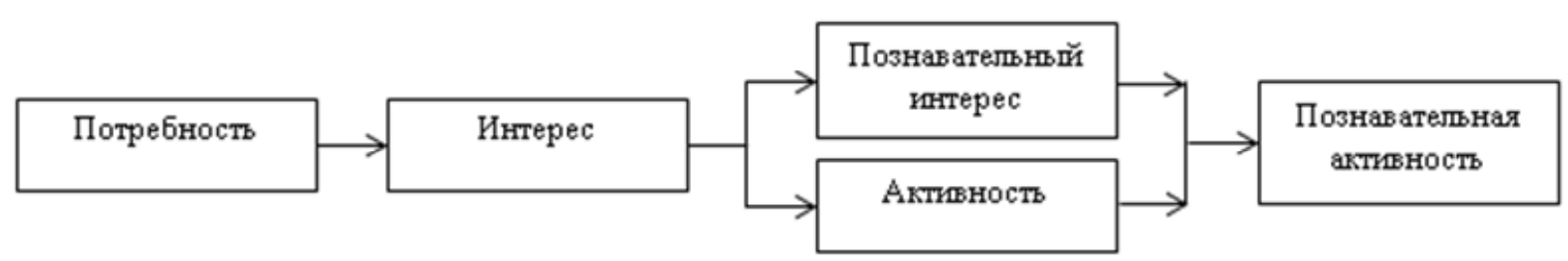

Рисунок 1. Система, отражающая логику развития познавательной активности.

Цель данной системы заключается в том, чтобы показать логику развития познавательной активности. Объектами системы являются: потребность, интерес, познавательный интерес, активность, познавательная активность. Они иерархично расположены, связаны последовательной логикой изложения. Вследствие перехода к следующему объекту системы происходит познавательное приращение, тем самым можно сделать вывод о единой концепции каждого объекта, что позволяет выделить у системы принцип целостности. 
Принцип изолированности заложен в наличии взаимодействия отдельных элементов системы (познавательный интерес и активность).

В случае рассмотрения отдельных объектов системы (познавательный интерес и активность) как подобъекты общего ее объекта, связывающий «интерес» и «познавательную активность» можно говорить о выполнении принципа делимости системы.

Наличие в научной и методической литературе описание отдельных элементов системы, а также самой системы (Ситаров, Шонин, 2017; Шонин, 2016) позволяет судить о принципе множественности и идентифицируемости.

Не представляется возможным изучать свойства, связи объектов системы, не имеющих теоретического и практического обоснования. Таким образом, если не зародить элементарный интерес к предмету изучения, то невозможно развить и познавательный интерес, а стало быть, и познавательную активность в том числе. А значит, принцип неопределенности также присущ нашей системе.

Согласно поставленной цели, результатом работы системы должна стать познавательная активность. Базой ее развития является категория «потребность». Для успешной и при этом оптимальной ее реализации, безусловно, важен контроль над связями между объектами данной системы, понимание цели и прогнозирование результата ее деятельности. Данная система строго структурирована по принципу перехода от более общего понятия к частному, что позволяет ее пронаблюдать и диагностировать ту или иную ступень развития, говорящую о том, что система отвечает принципу наблюдаемости.

Таким образом, проведя анализ, можно сделать вывод, что система отражающая логику развития познавательной активности содержит в себе принципы системности Ю. И. Черняка. В этой ситуации особую значимость приобретает изучение опыта реализации системного подхода, в основе которого лежит рассмотрение объектов как совокупности взаимосвязанных компонентов, при взаимодействии которых объект приобретает новые интегративные свойства, в теории обучения - в общем, и развитию познавательной активности - в частности.

\section{СПИСОК ЛИТЕРАТУРЫ}

Анохин, П. К. (1978) Философские аспекты теории функциональной системы. М. : Наука. 395 с.

Блауберг, И. В., Юдин, Э. Г. (1973) Становление и сущность системного подхода. М. : Наука. 274 с.

Ситаров, В. А., Шонин, М. Ю. (2017) Логика развития познавательной активности // Проблемы современного педагогического образования. Сер.: Педагогика и психология. Ялта : РИО ГПА. Вып. 55. Ч. 7. С. 77-86. 
Философский энциклопедический словарь (1983) / гл. ред. Л. В. Ильичев. М. : Советская энциклопедия. 836 с.

Черняк, Ю. И. (1975) Системный анализ в управлении экономикой. М.: Экономика. 193 с.

Шонин, М. Ю. (2016) О структурном анализе понятия «познавательный интерес» у школьников // Высшее образование для XXI: XIII Международная научная конференция. Москва, 8-10 декабря 2016 г.; Доклады и материалы. Секция 1. Педагогика и образование / отв. ред. А. А. Фортунатов. Часть 3. М. : Изд-во Моск. гуманит. ун-та. С. 88-94.

Дата поступления: 06.06.2017 2.

Ситаров Вячеслав Алексеевич - доктор педагогических наук, профессор, заведующий кафедрой педагогики и психологии высшей школы Московского гуманитарного университета. Адрес: 111395, Россия, г. Москва, ул. Юности, д. 5. Тел.: +7 (495) 374-74-59. Эл. адрес: sitarov@mail.ru

Шонин Максим Юрьевич - аспирант кафедры педагогики и психологии высшей школы Московского гуманитарного университета. Адрес: 111395 , Россия, г. Москва, ул. Юности, д. 5. Тел. +7 (982) 298-81-06. Эл. адрес: st_max_92@ mail.ru. Научный руководитель - д-р пед. н., проф. В. А. Ситаров.

Sitarov Viacheslav Alekseevich, Doctor of Pedagogy, Professor, Head, Department of Pedagogy and Psychology of Higher School, Moscow University for the Humanities. Postal address: 5, Yunosti St., Moscow, Russian Federation 111395. Tel.: +7 (495) 374-74-59.E-mail: sitarov@mail.ru

Shonin Maksim Yurievich, Postgraduate Student, Department of Pedagogy and Psychology of Higher School, Moscow University for the Humanities. Postal address: 5, Yunosti St., Moscow, Russian Federation 111395. Tel.: +7 (982) 29881-06. E-mail: st_max_92@mail.ru. Scientific Adviser - V. A. Sitarov, Doctor of Pedagogy, Professor.

\section{Для цитирования:}

Ситаров В. А., Шонин М. Ю. Системность в логике развития познавательной активности [Электронный ресурс] // Научные труды Московского гуманитарного университета. 2017, № 4. URL: http://journals.mosgu.ru/trudy/article/view/524 (дата обращения: дд.мм.гг.). DOI: 10.17805/trudy.2017.4.1 